\title{
COMUNICACOES BREVES \\ Influência do gênero em mapas cognitivos do mundo de universitários brasileiros
}

\author{
Munich V. S. Gomes e José Q. Pinheiro ${ }^{I}$ \\ Universidade Federal do Rio Grande do Norte
}

\begin{abstract}
Resumo
Investigamos mapas cognitivos do mundo de 82 estudantes de três cursos universitários, com o objetivo de verificar possíveis diferenças entre homens e mulheres quanto ao conhecimento dos países e preferência por eles. As representações mentais de mundo foram exteriorizadas através de mapas esquemáticos desenhados pelos próprios estudantes, ou mapas impressos com o contorno dos continentes preenchidos pelos estudantes com nomes e localização dos países. Poucos países foram bem conhecidos pelos estudantes, notadamente os das Américas do Norte e do Sul (número médio de 28,8 países, de um total possível de 192). Entre os 25 países com maiores médias, 24 tiveram médias mais elevadas para os homens, em alguns casos com diferenças estatisticamente significativas. Quanto à localização espacial dos países no mapa, dos 92 países conhecidos em comum, 76 (83\%) foram mais bem posicionados pelos homens. Dos 40 países mais citados quanto à preferência, 22 tiveram basicamente o mesmo grau de preferência para os dois grupos, 14 foram vistos mais positivamente pelos homens e apenas 4 pelas mulheres, embora nenhuma dessas diferenças tenha atingido significância estatística.

Palavras-chave: gênero; mapa cognitivo; mundo; conhecimento de países; preferência.
\end{abstract}

\footnotetext{
Abstract

Gender influence on cognitive maps of the world of Brazilian University students
} 
Key-words: gender; cognitive maps; world; knowledge of countries; preference
We analyzed cognitive maps of the world of 82 students of three university courses, to verify possible differences between men and women in regard to knowledge of countries and preference. The mental representations of the world were externalized by means of sketch maps drawn by the students or printed maps with the contour of continents filled by the students with names and location of the countries. Just a few countries were well known by the students, particularly in North and South America (average of 28.8 countries, out of a possible total of 192). Among the 25 countries with the highest means, 24 had higher means for the men, in some cases with statistically significant differences. In relation to the spatial location of the countries on the map, out of the 92 countries known in common, $76(83 \%)$ were better positioned by men. Among the 40 countries most mentioned in regard to preference, 22 were equivalent in preference for both groups, 14 were seen more positively by men and only 4 by the women, even though none of these differences reached statistical significance.

A utilização de mapas como instrumento de orientação é algo muito antigo na história da humanidade. Nossos antepassados nômades, sempre em busca de locais que lhes oferecessem melhores condições de sobrevivência, precisavam ter uma boa noção de espaço e assim poder usufruir melhor o ambiente. Era importante saber de onde vinham e para onde iam e, para tanto, os desenhos de vales e rios da região nas paredes das grutas eram importantes auxiliares.

Mapas ajudam os seres humanos a se orientar e facilitam a apreensão mental dos ambientes que se estendem para além do horizonte imediato. Sendo o mundo um ambiente tão amplo e, ao mesmo tempo tão importante, a todo momento as pessoas estão sendo expostas a mapas, globos e outras formas de representá-lo. A partir daí, vão in- 
trojetando informações provenientes dessas fontes e é de acordo com esse mundo internalizado (entre outros fatores) que as pessoas agem em relação ao mundo (Pinheiro, no prelo; Pinheiro e Silva, 1997).

Uma curiosidade vem à tona quando se fala em introjeção do mundo externo, ou representação mental do mapa do mundo. A questão é saber se há semelhanças e/ou diferenças decorrentes do gênero da pessoa considerada. Embora não tenhamos encontrado estudos que tratassem diretamente da questão do gênero em relação à representação mental de mapas do mundo, algumas referências apontam direções interessantes.

Davlins e Berstein (1995) demonstram, através de pesquisa sobre a relação entre habilidade espacial e gênero, que os homens são mais precisos na percepção de detalhes e cometem menos erros na reprodução de ambientes do que as mulheres, denotando melhor capacidade espacial. Este tipo de dado permite que se remeta a Mattheus $(1987 ; 1986)$, pois este sugere que as diferenças encontradas entre os gêneros são devidas aos diferentes modos que homens e mulheres possuem de entrar em contato com o meio ambiente. Tanto que Boardmam (1990) encontra pequenas diferenças entre os gêneros em desenhos de ambientes feitos por crianças de escola primária. Entretanto, à medida que a idade considerada vai aumentando (escola secundária), a performance dos meninos se aprimora, superando o desempenho das meninas. Estudos mais recentes sobre as diferenças entre os gêneros sugerem que em muitos casos elas são produzidas pelo meio sócio-cultural no qual estão inseridos homens e mulheres. Isto é, os ambientes produzem e reforçam tais comportamentos e características diferenciados (James, 1997). Há uma tendência cultural em agrupar meninos e meninas em ambientes diversos. O menino sai para jogar na pracinha, acompanha o pai ao jogo e ao trabalho, enquanto a menina fica protegida dentro de casa com suas bonecas, ou ajudando a mãe em tarefas domésticas, demorando assim a entrar em contato com o mundo. É dentro dessa tendência que meninos e meninas se tornam homens e mulheres.

É nesse contexto, portanto, que se insere o objetivo de nossa pesquisa, que era de investigar o desempenho de homens e mulheres 
em tarefas de exteriorização daquela representação interna do mapa do mundo.

\section{Método}

Nosso estudo contou com a participação de 82 estudantes da UFRN, sendo 46 mulheres e 36 homens, alunos do $1^{\circ}$ ano dos cursos de Arquitetura, Geografia e Psicologia. Nosso interesse principal era investigar o conhecimento que os participantes tinham dos países do mundo e qual a preferência que manifestavam pelos mesmos. Os instrumentos utilizados foram: mapa esquemático, que consiste num desenho do mapa do mundo feito à mão livre pelo participante; e dois mapas impressos apenas com o contorno dos continentes, sendo um com o eixo central nas Américas (Americêntrico) e o outro com o eixo central na Ásia (Sinocêntrico). Nos três casos os participantes eram instruídos a colocar no mapa todos os países de que conseguissem se lembrar. O conhecimento do país levava em conta a indicação pelo participante do "Nome", das fronteiras ("Contorno") e da "Localização" do país, combinando, portanto, aspectos verbais e espaciais de tal conhecimento. A seguir, pedíamos aos participantes que listassem países de que se lembravam, assinalando a preferência por aquele país em uma escala tipo Likert, com valores que iam de "3" a “+3", sem o "zero".

\section{Resultados e Discussão}

No grupo como um todo observamos que, do total de 192 países do mundo, 129 foram citados pelo menos uma vez por algum dos participantes. Já a média individual de países conhecidos foi de 28,8, o que corresponde a $15 \%$ do total. Será que nós temos pouca capacidade de armazenar informações desta natureza? Ou será que a forma como é ensinado e estimulado o uso de mapas de mundo prejudica o desempenho das pessoas no momento de fixar os países? Não se tem a pretensão, aqui, de dizer que as pessoas devem ter em mente todos, ou sequer, a maioria dos países do mundo. Queremos sim, chamar a atenção para o fato de que os países conhecidos pelas pessoas variam, basicamente, em torno de um pequeno conjunto de 
nações. $\mathrm{O}$ grupo de estudantes apresentou um bom conhecimento dos países da América do Norte e da América do Sul, e razoável da Europa. As demais regiões do planeta, em geral desconhecidas pelos participantes, apresentam uns poucos países medianamente mencionados pelos estudantes: na África, África do Sul e Egito; na América Central, Cuba; na Ásia, Japão; e na Oceania, Austrália e Nova Zelândia, o que confirma o padrão geral de conhecimento de universitários brasileiros observado em estudos anteriores (Pinheiro, no prelo; Pinheiro \& Silva, 1997). A representação mental observada aqui é muito coerente com aquela que as forças ideológicas permitem que se tenha, com as previsíveis repercussões frente à era da globalização.

Foram 92 os países mencionados em comum por homens e mulheres, tendo os homens aludido a um total de 119 países $(+27)$ e as mulheres $102(+10)$, o que indica uma cobertura quantitativamente mais rica dos países do mundo pelo grupo dos homens. Notamos, entretanto, que homens e mulheres tiveram basicamente o mesmo desempenho quando o fator considerado foi o "Nome" do país; ou seja, os nomes dos países foram guardados na memória, e resgatados de lá, de modo similar por ambos os grupos. Esse fato sugere que homens e mulheres estão igualmente expostos aos estímulos ambientais associados ao registro dos nomes dos países.

Porém, quando analisamos "Contorno" e "Localização" dos países, ocorreu um salto qualitativo nas diferenças entre homens e mulheres, pois aqueles demonstraram muito melhor desempenho no que diz respeito ao posicionamento dos países no mapa. Dos 92 países conhecidos em comum pelos dois grupos, 76 países (83\%) foram mais bem posicionados pelos homens do que pelas mulheres; estas se saíram melhor apenas nos demais 16 países (17\%). Além disso, dentre os 25 países mais bem conhecidos (maiores médias) pelo grupo em geral, 24 tiveram médias mais elevadas para os homens (em alguns casos com diferenças significativas, como Alemanha, África do Sul, França, Rússia, Colômbia e Austrália), contra apenas um país, Venezuela, melhor posicionado pelas mulheres.

Outro fato importante foi a média individual de países citados por homens e mulheres: 34,9 e 24, respectivamente. A diferença, cerca 
de 10 países, parece bastante, pois é aproximadamente um terço da média geral de todos os estudantes $(28,8)$.

Quanto à preferência, para o grupo como um todo, os países vistos como mais positivos foram os situados na Europa, enquanto os mais negativos estavam espalhados pela Ásia e África. Já aqueles países que se caracterizaram como ambivalentes (por terem sido vistos tanto positiva como negativamente) pertenciam, em sua maioria, à América do Sul.

Quando analisamos a questão do gênero, constatamos que os homens enxergam os países do mundo, em média, mais positivamente do que as mulheres. Dos 40 países mais citados quanto à preferência, 22 tiveram basicamente o mesmo grau de preferência para os dois grupos, 14 foram preferidos mais positivamente pelos homens e apenas 4 pelas mulheres. Será que as mulheres são mais críticas e/ou exigentes em relação aos países em geral? Os homens demonstraram ter uma preferência mais positiva pelo mundo, e isto pode favorecer a que eles se voltem mais para os mapas. Ou será que, por olharem muito para mapas, desenvolvem uma predileção maior pelos países do mundo?

\section{Conclusão}

A partir dos resultados analisados, fica em evidência que os homens têm a função espacial mais bem definida que as mulheres para a representação mental de mapas do mundo, como, aliás, fora demonstrado pelas pesquisas sobre conhecimento espacial em escala bem menor que a mundial (como ruas e bairros), tanto com adultos (Davlin \& Bernstein, 1995), como com crianças (Boardman, 1990).

Apesar da diminuição das desigualdades entre homens e mulheres, o papel social da classe masculina parece ainda favorecer seu melhor domínio do espaço, como no caso do nordeste brasileiro, região onde foi realizada esta pesquisa. Entretanto, o tema merece mais investigação pois, como apontado por James (1997), é necessário ir além das estereotipias, do que é próprio do sexo masculino e do sexo feminino, procurando entender as semelhanças e diferenças entre homens e mulheres a partir do contexto social em que se dá sua existência. 


\section{Referências}

Boardmam, D. (1990). Graphicacy Revisited: Mapping abilities and gender differences. Educational Review, 42(1), 57-64.

Davlins, A.S. \& Berstein, J. (1995). Interactive wayfinding: Use of cues by men and women. Journal of Environmental Psychology, 15(1), 23-38.

James, J. B. (1997). What are the social issues involved in focusing difference in the study of gender. Journal of Social Issues, 53(2), 213-232.

Mattheus, M. H. (1986). The influence of gender on the environmental cognition of young boys and girls. Journal of Genetic Psychology, 147(3), 295-302.

Mattheus, M. H. (1987). Sex differences in spatial competence: the ability of young children to map "primed" unfamiliar environments. Educational Psychology, 7(2), 77-90.

Pinheiro, J. Q. (no prelo). Determinants of cognitive maps of the world as expressed on sketch maps. Journal of Environmental Psychology.

Pinheiro, J. Q., \& Silva, J. A. F. (1997). Explorando aspectos cognitivos e afetivos de representações de mundo, através de mapas esquemáticos e questionários. Psico, 28(2), 171-182.

Munich V. S. Gomes é aluna do Nota $\quad{ }^{1}$ Participaram também os seguintes alunos do Curso de Formação de Psicólogos da UFRN: Homero A. Melo Jr., Suelaine V. M. Moraes, Waleska P. L. Santos e Heriane V. Silva.

Curso de Formação de Psicólogos da UFRN. José Q. Pinheiro é professor no Departamento de Psicologia da mesma universidade e coordenador do Grupo de Estudos Pessoa-Ambiente (GEPA). Correspondência, em nome do segundo autor, para: Caixa Postal 1507, Natal-RN, 59078-970, Brasil. TeleFax: (084) 215-3589. E-mail: pinheiro@cchla.ufrn.br.

\section{Sobre os autores}

